\title{
ANALYSIS OF THE LINKAGE EFFECT BETWEEN REGIONAL ECONOMIC DEVELOPMENT AND LOGISTICS COMPETITIVENESS IN CHINA
}

\author{
Wang XUEJIAO \\ Ningbo Dahongying University, Xueyuan Road No. 899, Yinzhou District, Ningbo city, \\ ZheJiang 315175, China.E-mail: bzhiwsmd@qq.com.
}

\begin{abstract}
Logistics industry, being the modern industry integrating information, forwarding, warehousing, and transportation, plays an important role in optimizing the industrial structure in regional economic development. There have been many experts and scholars interpreting the relationship between the level of regional economy and logistics industry from the aspect of econometric model. Referring to existing research results, Panel Vector Autoregressive Model and Factor Analysis are applied to study panel data of 5 coastal provinces in past 20 years and construct relevant indicators reflecting logistic competitiveness, the level of regional economy, and degree of openness in order to explore the linkage effect between logistic competitiveness and the level of regional economy. The results suggest that the 5 coastal provinces can merely achieve the long-term and steady development of regional economy by moving towards the linkage development between logistic industry and manufacturing industry.
\end{abstract}

Keywords: logistics industry, regional economy, Vector Autoregressive Model, linkage effect

\section{INTRODUCTION}

The economy in China grew rapidly after the reform and opening up; especially, the overall size, service level, and business environment in logistics industry after 2000 presented significant expansion and improvement. The total social logistics by 2011 reached 158 trillion yuan, 7 times higher than it in 2000 . After the "twelfth five-year" outline was issued by the central government, local governments also formulated a series of policies and systems to support the development of logistics industry for responding to the call of "enhancing logistics infrastructure". Although logistics industry in China was unprecedentedly developed, it also en- 
countered the bottleneck of imperfect infrastructure, unreasonable layout, lack of comprehensive logistics systems, and low logistics technology (Chen, 2012).

Logistics industry presents the characteristics of fundamentality, comprehensiveness, and service, which determines the close association with regional economic development. Research on the effect of logistics competitiveness and regional economic growth has become a key study on relevant fields. The linkage development between the two will directly affect the coordination and development of industries and present significant meanings on the optimization of regional industrial structure.

\section{DEVELOPMENT OF ECONOMY AND LOGISTICS DEVELOPMENT IN COASTAL AREAS}

Currently, the cost of the logistics industry is comparatively high while the logistics efficiency is comparatively low in China. Besides, the lack of effective policies worsens the entire logistics industry. The development of logistics industry varies in different provinces and regions that the linkage effect between regional economy and logistics development is studied. Five coastal provinces (Shandong, Jiangsu, Zhejiang, Fujian, and Guangdong) are selected in this study to exclude obvious geographical differences.

\subsection{Current development of logistics industry}

In terms of the scale, logistics industry has been highly emphasized in Guangdong, where the investment in logistics infrastructure construction is increased, a large number of ports and logistics parks are built, and transportation network is getting perfect to largely enhance the logistics transport capacity and service level. The logistics industry in the province has been leading other provinces (Liu, 2013). Fujian, located on the west of the strait, is the origin of maritime silk route, which establishes the critical status in oversea trade. The development of logistics industry in the province is relatively low, but the investment in the logistics infrastructure is increasing in past years. However, the management model is relatively dull so that the overcapacity of logistics industry in the area is considered adverse to local economic development. Both Jiangsu and Zhejiang are in the Yangtze River delta economic circle. The rapid development of logistics industry in Zhejiang has enlarged the scale to become a primary industry in the economic development. The development and advance of logistics industry has logistics parks constantly cluster. In Shandong, being a strong economic develop- 
ment province in China, logistics industry has become an important pillar industry. The investment in logistics industry in the province reached more than two hundred billion yuan in 2011, which was $9.5 \%$ lower than in 2010 , revealing the decrease of fixed investment growth rate in logistics industry that the province had larger space to promote the scale efficiency of logistics.

Logistics supply capacity reflects the level of regional logistics infrastructure in an area; the development of regional water, land and air transportation is a critical indicator to measure the level of logistics infrastructure. The level of logistics infrastructure in the five coastal provinces is obviously higher than it in inland provinces because of the better resources for the outstanding advantage for logistics industry development.

\subsection{Current situation of economic development}

Strong logistics demands, as the important prerequisite for the development of logistics industry, are directly affected by local economic strength that an area with advanced economy presents better logistics industry development. Shandong, Jiangsu, Zhejiang, Fujian, and Guangdong, five provinces with strong economic strength, show the GDP growth rate far above the national average. Under the orientation of international markets, the five provinces greatly develop processing trade to largely enhance the development of export-oriented economy. The total imports and exports of the five provinces in 2011 exceeded US\$2 trillion. Regarding the industrial structure, it is more reasonable in the five coastal provinces than those in the central and the west, as the first industry proportion has not been more than $10 \%$, and the economic development model focuses on the second and the third industries.

\section{EMPIRICAL ANALYSIS OF THE LINKAGE EFFECT BETWEEN THE LEVEL OF REGIONAL ECONOMY AND LOGISTICS COMPETITIVENESS}

Regional economic development is built on the basis of reasonable spatial allocation of resources and the linkage effect with logistics competitiveness mainly embodies in the logistics competitiveness being able to change geographical locations, reduce transportation costs, and extend border trade (Yang 2014). In other words, logistics would influence industry agglomeration and further affect the production output in this area. Hector seaman considered the imbalance of economic growth that different industrial development should be evaluated and assorted under given production resources. Competitive industries shall be first 
developed to stress on the linkage effect and resource configuration optimization effect induced by such industries. Based on such a theory, the linkage direction between economic development and logistics industry is uncertain (Zheng and $\mathrm{Lu} 2010$ ).

A lot of scholars have done quantitative or qualitative research on the linkage effect of regional economic development and logistics competitiveness, where the construction of a state, city, enterprise logistics competitiveness index system and Multiple Regression Analysis of time series data and various indicators are widely recognized. Nevertheless, such methods are longitudinal quantitative study, in which regression deviation is likely to occur because of multicollinearity and instability causing spurious regression (Teng 2011). Panel Vector Autoregressive Model (PVAR) presents the advantages of Vector Autoregressive Model and panel data to effectively ensure the large sample size so as to avoid errors caused by small sample size and further analyze the relationship among variables with variance decomposition. This study therefore applies such a model to analyze the relationship between logistics competitiveness and the level of regional economy in the five provinces.

\subsection{Panel Vector Autoregressive Model}

Vector Autoregressive Model uses simultaneous equations to effectively reduce the limitation on the economic relationship among variables. It obtains the dynamic relationship among endogenous variables by the regression of endogenous variable lag period. The model is widely used for various research and treatment of economics. Based on Vector Autoregressive Model, various models, such as PVAR and PVAR, are derived to expand the objects of Vector Autoregressive Model to panel data. It combines the advantages of both, with higher degree of freedom and less effect on the multicollinearity among independent variables.

\subsection{Indicator and model construction}

\subsubsection{Selection and integration of indicators}

Due to the close association between regional economic development and degree of openness, the higher degree of openness could attract more investment from international logistics enterprises to further promote logistics industry and regional economic development. Degree of openness is therefore selected as the endogenous variable for this research model. PVAR includes three variables of 
regional economic development, degree of openness, and logistics competitiveness. Scientific and reasonable indicators are required for defining the linkage relationship among variables. For logistics competitiveness, freight turnover, mileage of roads and railways, and total product of transportation and warehousing are utilized for measuring logistics demand, supply, and scale. For degree of openness, FDI (foreign direct investment) and total volume of imports and exports are selected. In consideration of total output and the rationality of industrial structure, GDP and GDP per capita as well as the added value of the first, the second, and the third industries are selected for regional economic development (Zhang and $\mathrm{Hu}$ 2012).

Considering that too many indicators in PVAR might affect the stability of the model or excessive dependent variables cannot be estimated, it is necessary to control the number of endogenous variables for the model. With Factor Analysis, the three indicators for logistics competitiveness are integrated into the indicator WULIU, the three indicators for degree of openness into the indicator KAIFANG, and the five indicators for regional economic development into the indicator JINGJI.

\subsubsection{Model construction}

There are certain differences in the level of economic development and logistics industry among the five coastal provinces, but they all belong to the conventional panel structure. Logistics competitiveness and degree of openness present time lag effect on regional economy that the effect is reflected after a period of time. Besides, logistics competitiveness, degree of openness, and the past level of regional economy would influence the change directions. Since PVAR presents the advantages of panel data and Vector Autoregressive Model, it could reflect the individual effect and time effect of vector as well as analyze the change direction of other variables under the impact of a variable to accurately and objectively reflect the linkage effect among regional economic development, degree of openness, and logistics competitiveness (Lei 2012). As lag orders would affect the degree of freedom and induce new parameter estimation problems that the lag order of PVAR is set 1 in this study. Equation (1) shows the PVAR model with the lag order set 1.

$$
y_{i t}=\alpha_{i}+\beta_{t}+\mu_{i t}+\Gamma y_{i t-1}
$$

where $y_{i t}$ is endogenous variable vector, $i$ and $t$ are province and year, respectively, $\Gamma$ is coefficient matrix $(3 \times 3)$, and $\alpha_{i}, \beta_{t}$, and $\mu_{i t}$ denote individual effects to present the heterogeneity of regional development and resources endowment as 
well as the time effect and residual to present the impact of time on endogenous variables, respectively.

\subsection{Empirical analysis}

\subsubsection{Descriptive Statistics of variables and indicator synthesis}

(1) Logistics competitiveness

Table 1. Descriptive Statistics of logistics competitiveness

\begin{tabular}{lcccc}
\hline Item & $\mathrm{N}$ & Mean & $\begin{array}{c}\text { Standard } \\
\text { deviation }\end{array}$ & Min Max \\
\hline $\begin{array}{l}\text { Total product of transportation and } \\
\text { warehousing/hundred million yuan }\end{array}$ & 240 & 612 & 473 & $19 \sim 2,311$ \\
Roads and railways total mileage/km & 240 & 75,420 & 52,114 & $23,877 \sim 23,7411$ \\
Freight turnover/hundred million tones & 240 & 2,597 & 2,433 & $196 \sim 12,674$ \\
\hline Item & Variance & Kurtosis & Partial degree \\
\hline Total product of transportation and & 318,141 & $0.677 \pm 0.419$ & $1.133 \pm 0.201$ \\
warehousing/hundred million yuan & & & & \\
Roads and railways total mileage/km & $2.720 \times 109$ & $1.723 \pm 0.420$ & $1.533 \pm 0.211$ \\
Freight turnover/hundred million tones & 602,0741 & $3.766 \pm 0.421$ & $1.762 \pm 0.210$ \\
\hline
\end{tabular}

Table 1 shows Descriptive Statistics of logistics competitiveness in the five provinces (panel data are recorded in the database of China Economics and statistical yearbooks of the 5 provinces). WULIU, integrated by the three indicators for logistics competitiveness with Factor Analysis, is tested by KMO and Bartlett in this study. The result shows the test values of KMO and Bartlett $>0.8$ and $<0.05$, respectively, revealing the correlation matrix being a non-unit matrix that Factor Analysis could be proceeded. Principal Component Analysis shows the variance contribution rate of the first principal component $93.041 \%$ that it is reasonable to substitute the component for the original indicators. The relationship with the three indicators is shown as

WULIU $=$ total product of transportation and warehousing $\times 0.958+$ total mileage of highway railway $\times 0.967+$ freight turnover $\times 0.950$

(2) Level of regional economy

Table 2 shows Descriptive Statistics of the level of regional economy. JINGJI, integrated by the 5 indicators with Factor Analysis, is tested by KMO and Bartlett, and the correlation matrix is conformed as a non-unit matrix that Factor 
ANALYSIS OF THE LINKAGE EFFECT BETWEEN REGIONAL ECONOMIC DEVELOPMENT... 245

Table 2. Descriptive Statistics of the level of regional economy

\begin{tabular}{lcccc}
\hline Item & $\mathrm{N}$ & Mean & $\begin{array}{c}\text { Standard } \\
\text { deviation }\end{array}$ & Min Max \\
\hline $\begin{array}{l}\text { Primary industry/hundred million } \\
\text { yuan }\end{array}$ & 240 & 969 & 652 & $72.20 \sim 3,977$ \\
$\begin{array}{l}\text { Secondary industry/hundred million } \\
\text { yuan }\end{array}$ & 240 & 6,108 & 4,402 & $83.10 \sim 26,557$ \\
Tertiary industry/hundred million yuan & 240 & 4,883 & 3,644 & $67.94 \sim 25,091$ \\
Per capita GDP/yuan & 240 & 15,432 & 15,009 & $808.0 \sim 63,347$ \\
GDP/hundred million yuan & 240 & 9,410 & 11,971 & $-677.5 \sim 53,317$ \\
\hline Item & Variance & Kurtosis & Skewness degree \\
\hline $\begin{array}{l}\text { Primary industry/hundred million } \\
\text { yuan }\end{array}$ & 612,984 & $2.739 \pm 0.421$ & $1.536 \pm 0.199$ \\
Secondary industry/hundred million & $4.204 \times 107$ & $1.652 \pm 0.422$ & $1.562 \pm 0.210$ \\
yuan & & & & \\
Tertiary industry/hundred million yuan & $2.550 \times 107$ & $3.106 \pm 0.421$ & $1.832 \pm 0.211$ \\
Per capita GDP/yuan & $2.304 \times 108$ & $0.499 \pm 0.420$ & $1.206 \pm 0.200$ \\
GDP/hundred million yuan & $1.429 \times 108$ & $2.837 \pm 0.419$ & $1.84 \pm 40.212$ \\
\hline
\end{tabular}

Analysis could be preceded. Principal Component Analysis presents the variance contribution rate of the first principal component $93.021 \%$ that it is reasonable to substitute the component for the original indicators. The relationship with the indicators is shown as

JINGJI $=$ the first industry $\times 0.938+$ the second industry $\times 0.994+$ the third industry $\times 0.987+$ GDP per capita $\times 0.925+$ GDP $\times 0.968$

(3) Degree of openness

Table 3. Descriptive Statistics of degree of openness

\begin{tabular}{lccccc}
\hline Item & $\mathrm{N}$ & Mean & $\begin{array}{c}\text { Standard } \\
\text { deviation }\end{array}$ & Min Max \\
\hline $\begin{array}{l}\text { FDI/ten thousand US dollars } \\
\text { Total exports/hundred million }\end{array}$ & 240 & 64,6200 & 6.7154 & $1801 \sim 332,5410$ \\
US dollars & 240 & 638 & 992.411 & $6.92 \sim 5,326$ \\
$\begin{array}{l}\text { Total imports/hundred million } \\
\text { US dollars }\end{array}$ & 240 & 442 & 709.415 & $2.03 \sim 3,820$ \\
\hline Item & Variance & \multicolumn{2}{c}{ Kurtosis } & \multicolumn{2}{c}{ Skewness degree } \\
\hline FDI/ten thousand US dollars & $4.412 \times 1011$ & 2.301 & 0.419 & 1.405 & 0.221 \\
$\begin{array}{l}\text { Total exports/hundred million } \\
\text { US dollars }\end{array}$ & 983,651 & 6.533 & 0.420 & 2.487 & 0.209 \\
$\begin{array}{l}\text { Total imports/hundred million } \\
\text { US dollars }\end{array}$ & 514,274 & 6.794 & 0.432 & 2.564 & 0.205 \\
\hline
\end{tabular}


Table 3 displays Descriptive Statistics of degree of openness. The three indicators are integrated with the same method, and Principal Component Analysis shows the variance contribution rate of the first component $92.494 \%$ that it is reasonable to substitute the component for the original indicators. The relationship with the indicators is shown as

KAIFANG $=$ FDI $\times 0.918+$ total imports $\times 0.979+$ total exports $\times 0.976$

\subsubsection{Empirical results}

As instable variables would affect the calculation result of the model, it is necessary to test the balance. LLC is applied to test WULIU, KAIFANG, and JINGJI in this study. The results show the stability of the variables that PVAR model can be set up. The eventually established first-order lag PVAR model presents

$$
\begin{aligned}
& \text { POWER }_{i t}=2.150 O P E N_{i t-1}+1.956 \text { POWER }_{i t-1}+1.380 \text { ECONO }_{i t-1}+\mu_{i t}^{1} \\
& \left(3.810^{*}\right) \quad(3.195 *) \\
& \text { OPEN }_{i t}=0.379 O P E N_{i t-1}+1.992 P^{2} O W E R_{i t-1}+0.672 E C O N O_{i t-1}+\mu_{i t}^{2} \\
& \left(7.102^{*}\right) \quad(1.071) \quad(1.460) \\
& E_{C O N O}=1.766 O P E N_{i t-1}+1.508 P O W E R_{i t-1}+1.340 E C O N O_{i t-1}+\mu_{i t}^{3} \\
& (4.502 *) \quad\left(4.101^{*}\right) \quad\left(2.166^{* *}\right)
\end{aligned}
$$

(Note: * indicates the significance under $1 \%$; ** shows the significance under $5 \%$ ) From Equation (2), the influence coefficient and regression coefficients of JINGJI on WULIU appear 1.380 and 1.380 , respectively, revealing the positive effect of regional economy on logistics competitiveness. To some degree, regional economy could pull and promote logistics competitiveness, but the insignificant regression coefficient indicates that the level of regional economy is not the major factor in logistics competitiveness. The influence coefficients of KAIFANG and WULIU on WULIU appear 2.150 and 1.956, respectively. The regression coefficients present significant characteristics ( $1 \%$ level) that degree of openness and logistics itself could remarkably promote logistics competitiveness.

From Equation (3), the influence coefficient of WULIU on KAIFANG is 1.992, and the regression coefficient is significant, revealing that the more complete of 
logistics infrastructure, the more advance of logistics industry to enhance foreign import and export trade and attract more foreign investment. The positive effects of JINGJI and KAIFANG on KAIFANG are not significant.

From Equation (4), JINGJI, KAIFANG, and WULIU would affect the level of regional economy, with the influence coefficients 1.340, 1.340, and 1.508, respectively. The regression coefficients show significant characteristics $(5 \%$ and $1 \%$ levels). It indicates the remarkably positive effects of logistics competitiveness, degree of openness, and regional economy on regional economic development and proves that logistics development could promote regional economic development.

\subsubsection{PVAR variance decomposition}

To further define the relationship among the level of regional economy, degree of openness, and logistics competitiveness, JINGJI, KAIFANG, and WULIU are proceeded variance decomposition (Table 4).

From Table 4, the variance decomposition of vectors does not appear obvious changes when $\mathrm{S}$ is set 10,20, and 30, showing the better convergence of the model. JINGJI presents the largest effect, $41.4 \%$, on logistics competitiveness, followed by KAIFANG, 30.4 30.5\%, and the effect of itself appears the least $28.1 \sim 28.2 \%$. In regard to degree of openness, JINGJI reveals the largest effect, $41.1 \sim 41.3 \%$, followed by the effect of itself, and WULIU the least, $28.1 \sim 28.3 \%$. Regarding the level of regional economy, JINGJI presents the largest effect, $41.1 \sim 41.3 \%$, followed by KAIFANG, $30.5 \sim 30.6 \%$, while WULIU, the least, appears merely $28.1 \sim 28.4 \%$.

Table 4. Variance decomposition of JINGJI, KAIFANG, and WULIU

\begin{tabular}{lcccc}
\hline & S & WULIU & KAIFANG & JINGJI \\
\hline WULIU & 10 & 0.282 & 0.304 & 0.414 \\
KAIFANG & 10 & 0.283 & 0.306 & 0.411 \\
JINGJI & 10 & 0.284 & 0.305 & 0.411 \\
\hline WULIU & 20 & 0.281 & 0.305 & 0.414 \\
KAIFANG & 20 & 0.281 & 0.306 & 0.413 \\
JINGJI & 20 & 0.281 & 0.306 & 0.413 \\
\hline WULIU & 30 & 0.281 & 0.305 & 0.414 \\
KAIFANG & 30 & 0.283 & 0.306 & 0.411 \\
JINGJI & 30 & 0.281 & 0.306 & 0.413 \\
\hline
\end{tabular}




\subsubsection{Result explanation}

PVAR model is applied in this study to analyze the panel data of regional economy, degree of openness, and logistics industry in the 5 coastal provinces in past 20 years. The results show the notable promotion effect of degree of openness and logistics competitiveness on regional economic development in the 5 coastal provinces. The conclusion also proves "logistics promotion theory" (Xu and Huang 2011), The research outcomes present that logistics industry is largely affected by degree of openness that the higher degree of openness would more obviously promote logistics competitiveness, as foreign logistics enterprises would generate technology spillover in the early stage of investment in domestic markets to enhance the development of domestic logistics industry. Nevertheless, in the late stage of investment, competition in domestic logistics markets becomes fierce, the market is saturated, and domestic logistics enterprises present relatively weak technology and capitals so that domestic logistics industry development is inhibited.

The research result also shows that logistics competitiveness of the five coastal provinces, under the promotion of regional economic development, is not effectively enhanced, revealing that economic development is not the major factor in logistics competitiveness. Such a result is different from the reports of other domestic studies, possibly because the 5 coastal provinces focus on export industry development and investment in manufacturing, but are lack of investment in logistics industry, in the early stage of economic development. Accordingly, logistics competitiveness can hardly be promoted when the level of regional economy is promoted in the late stage. An unbalanced growth relationship appears between the level of regional economy and logistics competitiveness (Zhu 2014). This empirical study finds out the positive effect of logistics competitiveness on the level of regional economy. Apparently, the linkage development between regional economy and logistics competitiveness could ensure the long-term and steady growth and balanced development of local economy and logistics industry.

\section{CONCLUSION}

Logistics, as an emerging industry with the characteristics of comprehensiveness, fundamentality, and services, presents complex linkage effects with regional economic development. Based on "economy pull-up theory" and "logistics promotion theory", 5 coastal provinces in China are studied the panel data in past two decades in order to avoid the problems of short sample period in time series and low degree of freedom. PVAR model is applied to analyze the individual effect and time effect of panel data. It is discovered that logistics competitiveness could 
obviously enhance regional economic development in the 5 provinces, while regional economic development could not promote logistics competitiveness and hinders the promotion of logistics competitiveness in the lag period. In this case, the development of logistics industry in the 5 coastal provinces is highly emphasized and the investment in logistics industry would be increased within a period in the future, in order to enhance the linkage development between regional economy and logistics competitiveness and realize the stable and orderly development of local economy.

\section{ACKNOWLEDGEMENTS}

1. Phase achievements on Research on Countermeasure \& Policy of speeding up the construction of the Ningbo Port rail-sea intermodal transportation comprehensive experimental area (2015A10078).

2. Phase achievements on the construction of Zhejiang province sea linkage logistics system and optimization as the target of Free trade azone (2014SJYB01).

3. Phase achievements on Research on commodity logistics financial operation mode (1320133010).

\section{REFERENCES}

Chen Jia-Hai (2012). Correlation Analysis of Logistics Industry Development and Regional Economy - A case study on Tianjin and Shanghai. Science \& Technology Progress and Policy, 29(23), 44-49.

Lei Xun-ping (2012). Interactive Development between Regional Logistics and Regional Economy in An Hui. Journal of Shanghai Business School, 2(1), 17-22.

Liu Fen (2013). Research on Logistics and Regional Economic Development from Space-time Perspective. Journal of Yunnan Administration, 2(2), 230-231.

Teng Jia (2011). TPL and Coordinated Development of Industrial Clusters. Logistics Technology, 30(7), 36-45.

Xu Qian and Huang Zu-qing (2011). Interaction between Regional Logistics and Regional Economic Development- Zhejiang as an example. Statistics and Decision, (9), 116-129.

Yang Dao-jing (2014). Effects of Modern Logistics Industry Development on Regional Economy in Chengdu. Logistics Engineering and Management, (9), 46-47.

Zhang Jian-sheng \& Hu Xiu-zhong (2012). Research on Coupling Harmony between Regional Logistics and Regional Economics. Railway Transport and Economy, 34(1), 50-55.

Zheng Hong-ling \& Lu Li-li (2010). Collaborative Logistics Research Based on Three Industries of Regional Economy: Taking Hebei Province as an Example. Value Engineering, 29(14), 14-16.

Zhu Lan-lan (2014). Port Logistics gather momentum space and its effect on the regional economy analysis. Logistics Technology, (9), 246-258. 